\title{
openheart Potential impact of a modest reduction in salt intake on blood pressure, cardiovascular disease burden and premature mortality: a modelling study
}

\author{
Leopold Ndemnge Aminde, ${ }^{1,2}$ Linda J Cobiac, ${ }^{3} \mathrm{~J}$ Lennert Veerman ${ }^{1,4}$
}

\begin{abstract}
- Additional material is published online only. To view please visit the journal online (http://dx.doi.org/10.1136/ openhrt-2018-000943).
\end{abstract}

To cite: Aminde LN, Cobiac LJ, Veerman JL. Potential impact of a modest reduction in salt intake on blood pressure,

cardiovascular disease burden and premature mortality: a modelling study. Open Heart 2019;6:e000943. doi:10.1136/ openhrt-2018-000943

Received 3 October 2018 Revised 16 November 2018 Accepted 20 December 2018

Check for updates

(c) Author(s) (or their employer(s)) 2019. Re-use permitted under CC BY-NC. No commercial re-use. See rights and permissions. Published by BMJ.

${ }^{1}$ Faculty of Medicine, School of Public Health, The University of Queensland, Brisbane, Queensland, Australia

${ }^{2}$ Non-communicable Diseases Unit, Clinical Research

Education, Networking and

Consultancy (CRENC), Douala, Cameroon

${ }^{3}$ Nuffield Department of

Population Health, University of Oxford, Oxford, UK

${ }^{4}$ School of Medicine, Griffith University, Gold Coast, Queensland, Australia

Correspondence to Dr Leopold Ndemnge Aminde; I. aminde@uq.net.au

\section{ABSTRACT}

Objective To assess the potential impact of reduction in salt intake on the burden of cardiovascular disease (CVD) and premature mortality in Cameroon.

Methods Using a multicohort proportional multistate life table model with Markov process, we modelled the impact of WHO's recommended $30 \%$ relative reduction in population-wide sodium intake on the CVD burden for Cameroonian adults alive in 2016. Deterministic and probabilistic sensitivity analyses were conducted and used to quantify uncertainty.

Results Over the lifetime, incidence is predicted to decrease by $5.2 \%$ (95\% uncertainty interval (UI) 4.6 to 5.7) for ischaemic heart disease (IHD), 6.6\% (95\% UI 5.9 to 7.4 ) for haemorrhagic strokes, $4.8 \%$ (95\% UI 4.2 to 5.4 ) for ischaemic strokes and $12.9 \%$ (95\% UI 12.4 to 13.5) for hypertensive heart disease (HHD). Mortality over the lifetime is projected to reduce by $5.1 \%$ (95\% UI 4.5 to 5.6) for IHD, by $6.9 \%$ (95\% UI 6.1 to 7.7$)$ for haemorrhagic stroke, by $4.5 \%$ (95\% Ul 4.0 to 5.1$)$ for ischaemic stroke and by $13.3 \%$ (95\% UI 12.9 to 13.7$)$ for HHD. About 776400 (95\% UI 712600 to 841200 ) healthadjusted life years could be gained, and life expectancy might increase by 0.23 years and 0.20 years for men and women, respectively. A projected $16.8 \%$ change (reduction) between 2016 and 2030 in probability of premature mortality due to CVD would occur if population salt reduction recommended by WHO is attained.

Conclusion Achieving the $30 \%$ reduction in sodium intake recommended by WHO could considerably decrease the burden of CVD. Targeting blood pressure via decreasing population salt intake could translate in significant reductions in premature CVD mortality in Cameroon by 2030.

\section{INTRODUCTION}

High blood pressure (BP) is the leading risk factor for cardiovascular disease (CVD) globally, affecting over a billion adults. ${ }^{1}$ Adeloye and Basquill have shown that the number of individuals with hypertension in Africa increased from 54 million in 1990 to 130 million in 2010, with a projected increase to 216 million cases by $2030 .^{2}$ In Cameroon, a nationwide survey including over 15000 adults

\section{Key messages}

What is already known about this subject?

- Previous studies especially from high-income countries have shown that salt (sodium) intake is strongly related with blood pressure and cardiovascular disease (CVD). However, there is limited evidence exploring this relationship from Africa. About one in three adult Cameroonians have an elevated blood pressure, with reported high stroke mortality rates.

What does this study add?

- This is the first study from Cameroon and Africa as a whole to assess the WHO-recommended $30 \%$ reduction in salt intake on population health (burden of disease), its impact on life expectancy and premature CVD mortality by 2030.

How might this impact on clinical practice?

- Clinicians and policy-makers in Africa should, among others, lay particular emphasis on reduction in salt intake, as this has substantial impact on blood pressure, CVD mortality and overall population health.

revealed an age-adjusted hypertension prevalence of $29.7 \%$, with only $14 \%$ being aware of their status. ${ }^{3}$ Data from a hospital-based trend study in the capital city showed that stroke admission rates in medical wards increased from $2.5 \%$ in 1999 to $13.1 \%$ in 2012, with a significantly increasing stroke mortality from $14.4 \%$ to $22.4 \%$ over the same time period. ${ }^{4}$ In a recent echocardiographic study, hypertensive heart disease (HHD) (43.2\%), cardiomyopathies $(17.6 \%)$ and ischaemic heart disease (IHD) $(10 \%)$ were the major causes of heart disease among adults in the south-west region of Cameroon. ${ }^{5}$ These data underscore the urgent need for strategies to address this CVD burden.

The UN has set a target of a $30 \%$ reduction in premature mortality from non-communicable diseases (NCDs) by 2030. In 2013, WHO published a global action plan for the 
prevention and control of NCD 2013-2020. Among the nine voluntary global targets contained in this plan is a $30 \%$ relative reduction in mean population salt intake. ${ }^{6}$ These global recommendations for population-wide reduction in salt intake are supported by overwhelming evidence on the causal relationship between salt intakes, $\mathrm{BP}$ and $\mathrm{CVD}^{7}$ As of 2010, sodium intake levels in Cameroon were estimated at $2100 \mathrm{mg}(\sim 5.4 \mathrm{~g}$ salt $)$ per day, with an average of $2200 \mathrm{mg}(\sim 5.7 \mathrm{~g}$ salt $)$ in men. ${ }^{8}$ This is above the WHO-recommended maximum of 2000 $\mathrm{mg}$ per day and the $1500 \mathrm{mg}$ per day maximum that is proposed for blacks in the American Heart Association guidelines. ${ }^{9} 10$ In the UK in 2010, the National Institutes for Health and Care Excellence proposed a target to reduce population levels of salt intake to a maximum of 3 g salt ( 1200 mg sodium) by $2025 .^{11}$

With the exception of South Africa, ${ }^{12}$ there is limited evidence on the potential impact of salt reduction on CVD in Africa and none from Cameroon. Due to the growing disease burden due to BP and CVD in Cameroon, we set out in this study to model the potential impact of reducing current salt intake levels on the CVD burden in the adult Cameroonian population.

\section{METHODS}

\section{Estimating the effect of salt on BP, and BP on CVD}

We used evidence from a Cochrane systematic review and meta-analysis of trials. ${ }^{7}$ This study was used because they included only trials for which salt reduction interventions were evaluated over a minimum duration of 4 weeks. Such duration is considered relevant when evaluating the public health impact of salt reduction interventions. ${ }^{713}$ In their analysis, the authors found that (overall) a reduction of salt by $4.4 \mathrm{~g}$ led to a $4.18 \mathrm{~mm} \mathrm{Hg}(95 \% \mathrm{CI}$ 3.18 to 5.18) drop in systolic blood pressure (SBP). In black populations, the same $4.4 \mathrm{~g}$ salt reduction led to a $7.83 \mathrm{~mm} \mathrm{Hg}$ drop in SBP for hypertensive people and $4.02 \mathrm{~mm} \mathrm{Hg}$ drop in SBP for normotensive people. We used this latter relationship to model the impact of salt on SBP. See online supplementary file for model input data and sources.

\section{Disease epidemiological modelling}

The Global Burden of Disease (GBD) 2016 study provides relative risks for various risk factor and outcome pairs. ${ }^{14}$ We used relative risks and epidemiological estimates (incidence, prevalence, mortality) from the GBD study of diseases for which there is strong evidence for a causal link with SBP to model future disease burden. The diseases modelled were IHD, ischaemic stroke, haemorrhagic stroke and HHD. Each of the disease estimates were entered into DISMOD II software. ${ }^{15}$ Through a set of mathematical modelling equations, DISMOD II generates estimates for other epidemiological parameters that are otherwise unavailable (eg, case fatality) using at least three input data estimates (here, incidence, remission and mortality). This was done by sex and 5-year age groups, while additionally enforcing consistency in the data. ${ }^{15}$ The years lived with disability (YLD) due to each disease by sex and age group are also used to calculate the disability weight. The disease-specific YLDs are divided by their prevalence to obtain the 'disability weight (DW)' for each disease, which we further adjusted for comorbidities. These DWs (a numerical depiction of the severity of health loss due to a disease or health state) reflect the change in quality of life due to the various diseases and are used in calculation of the health-adjusted life years.

\section{Health impact assessment modelling}

We use a multicohort proportional multistate life table (MSLT) model with state-transition (Markov) property to estimate the salt reduction policy impact on CVD burden over the lifetime of the 2016 Cameroonian population. The proportional MSLT is an extension of the simple life table; it was used for its added capacity to deal with comorbidity or multiple diseases. ${ }^{16}$ The MSLT contains the reference population stratified by sex and 5-year age groups, the outcomes of which are compared with those for an identical population for whom the $30 \%$ salt reduction impact is assessed. As described above, we model the impact of change in sodium on SBP and subsequently SBP on CVD burden. Each of the BP-related diseases is explicitly modelled via transition probabilities that govern the movement of the population between four states (healthy, diseased, death from cardiovascular disease and death from other cause). The disease models are linked to the main life table through the potential impact fraction. ${ }^{17}$ Equation 1 (online supplementary file) calculates the proportional impact of change in exposure to BP (with and without change in sodium) on the occurrence of new CVD events. This new incidence leads to changes in prevalence and mortality later on, compared with the reference population exposed to stable sodium levels. Together with disease-related changes in quality of life previously calculated for every sex and 5-year age group, all these disease changes feed back into the life table with a new hypothetical population. The hypothetical population is identical to the (reference) adult Cameroonian population, but additionally receives the 'intervention', allowing calculation of new life expectancies and health-adjusted life years (HALYs). These calculations for the stratified (by sex and 5-year age group) cohorts are simulated with 1-year cycle lengths until everyone dies or reaches the age of 100 years for both the reference and hypothetical intervention populations. The differences in outcomes (change in incidence, mortality, life expectancy and HALYs) between these two populations are estimated to determine the impact of the intervention.

\section{Estimating probability of premature mortality}

Using the approach presented in the WHO NCD Global Monitoring Framework, ${ }^{18}$ we estimate the unconditional probability of dying between ages 30 and 70 years from the combined CVDs by the year 2030, with 2016 as base year. In contrast to the rest of our analysis, which takes 
a cohort perspective, this calculation takes a period perspective, analogous to the way life expectancies are normally calculated. Age-specific death rates (by 5-year age groups) calculated from the life table (described above) are translated to probabilities of death in the 5 -year age range using Equation 2. Then, the unconditional probability of mortality between 30 and 70 years is estimated using Equation 3 (online supplementary file). These calculations are performed with and without the impact of salt reduction, to estimate the potential change in premature mortality that may result from achieving reduction in population salt intake between 2016 and 2030, given current 2016 mortality rates.

\section{Sensitivity/scenario and uncertainty analysis}

The main analysis presents undiscounted future health outcomes. Sensitivity analysis was carried out to explore the impact of applying varying discount rates to $3 \%$ and $5 \%$. We also test the impact of $10 \%$ and $20 \%$ reduction in current salt intakes, and finally, we vary the sodiumBP relationship, from that derived for black-only ethnic populations, with estimates pooled across all ethnicities. We incorporated uncertainty in relative risks (log-normal distribution) and the impact of change in $\mathrm{BP}$ due to change in sodium (normal distribution). Probabilistic sensitivity analysis was performed to quantify the uncertainty in our results using Monte Carlo simulations, implemented with the Ersatz software, ${ }^{19}$ with 2000 iterations.

\section{RESULTS}

Achieving the population-wide reduction in salt intake by $30 \%$ (ie, by $\sim 1.7 \mathrm{~g} /$ day for men and $1.5 \mathrm{~g} /$ day for women) in Cameroon could lead to significant changes in BP-related CVD burden in adult Cameroonians. Figure 1 shows the potential shifts in SBP distributions of the youngest and oldest age groups for men and women that could be observed with this reduction salt intake.

\section{IHD incidence and mortality}

Over the first 10 years (ie, by 2025), our model predicts that decreasing current salt intake by $30 \%$ could reduce the overall number of new cases of IHD by approximately 15800 (95\% uncertainty interval (UI) 14100 to 17400 ), equivalent to a $7.3 \%$ (95\% UI 6.5 to 8.1 ) reduction. This is almost double in men compared with women (10 200 (95\% UI 8800 to 11600 ) vs 5900 (95\% UI 5400 to 6300 )). Over the lifetime, up to 58200 (95\% UI 51 600-64 800) new cases of IHD would be prevented for adult Cameroonians alive in 2016. These effects were predicted to be greater for men, reducing by 34600 (95\% UI 28 900-40 200) cases compared with 23600 (95\% UI 21 800-25 300) for women. Mortality from IHD was similarly predicted to

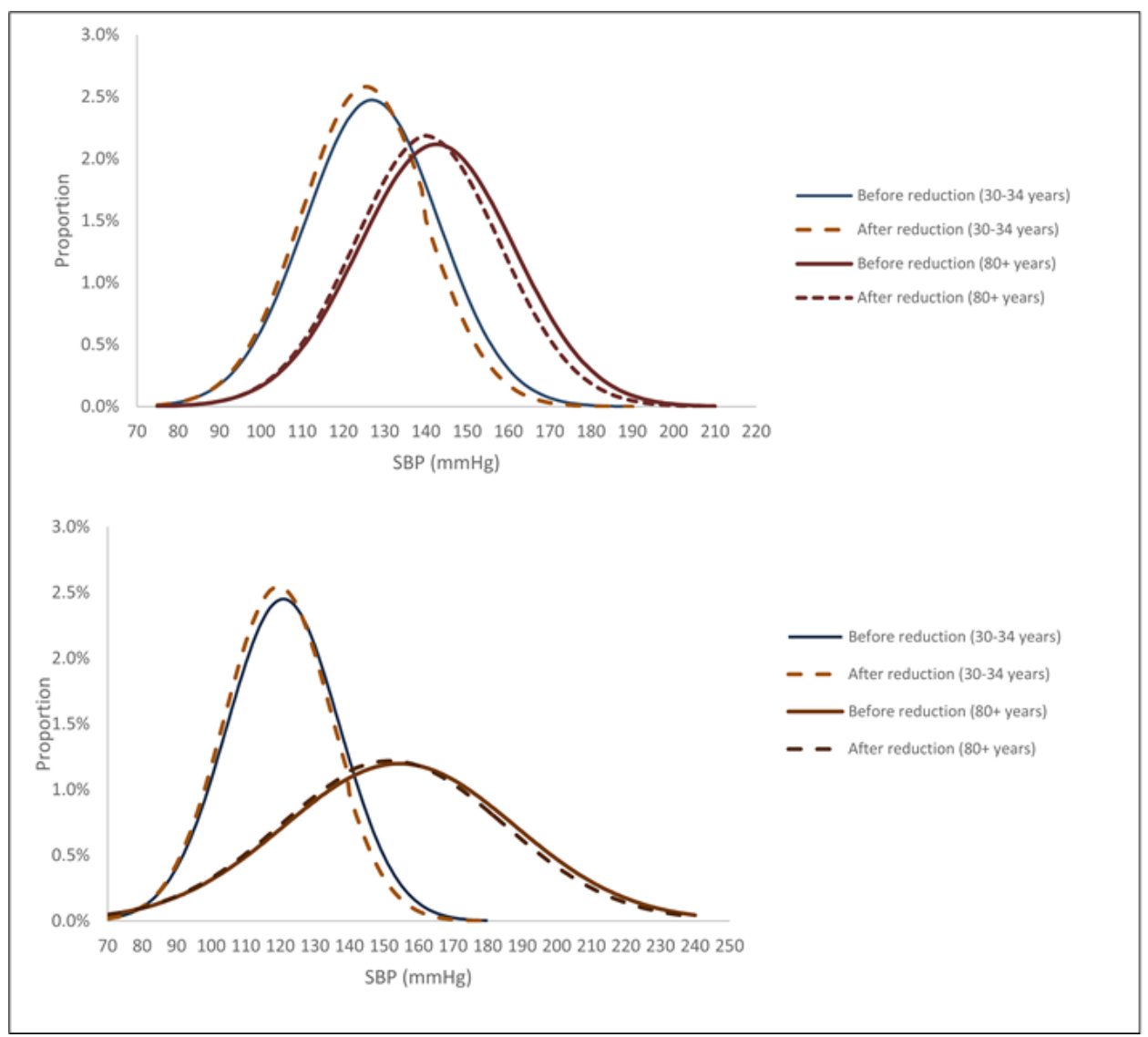

Figure 1 Projected shifts in systolic blood pressure (SBP) distribution for adult men (above) and women (below) following reduction in salt intake. 
Table 1 Reduction in incidence and mortality for ischaemic heart disease by sex due to $30 \%$ reduction in current salt intake in the 2016 adult Cameroonian population

\begin{tabular}{|c|c|c|c|c|c|c|}
\hline \multirow{3}{*}{$\begin{array}{l}\text { Year(s) } \\
\text { Incidence }\end{array}$} & \multicolumn{6}{|c|}{ Ischaemic heart disease } \\
\hline & \multicolumn{2}{|l|}{ Male } & \multicolumn{2}{|l|}{ Female } & \multicolumn{2}{|l|}{ Total } \\
\hline & n (95\% UI) & \% (95\% UI) & n (95\% UI) & \% (95\% UI) & n (95\% UI) & $\%(95 \%$ UI) \\
\hline $\begin{array}{l}\text { Year } 1 \text { to } 10 \\
2016-2025\end{array}$ & $10200(8800-11600)$ & $7.9(6.8-9.0)$ & $5900(5400-6300)$ & $6.4(5.8-6.9)$ & $15800(14100-17400)$ & $7.3(6.5-8.1)$ \\
\hline $\begin{array}{l}\text { Year } 1 \text { to } 20 \\
2016-2035\end{array}$ & 20200 (17 500-22 900) & $7.6(6.6-8.5)$ & 11700 (10 900-12 400) & $6.1(5.7-6.5)$ & 31900 (28 800-35 100) & $6.9(6.2-7.6)$ \\
\hline $\begin{array}{l}\text { Year } 1 \text { to } 25 \\
2016-2040\end{array}$ & $24700(21300-28000)$ & $7.3(6.3-8.3)$ & $14700(13800-15600)$ & $5.9(5.5-6.3)$ & $39400(35500-43300)$ & $6.7(6.1-7.4)$ \\
\hline \multicolumn{7}{|l|}{ Mortality } \\
\hline $\begin{array}{l}\text { Year } 1 \text { to } 5 \\
2016-2020\end{array}$ & $800(700-900)$ & $7.1(6.0-8.2)$ & $300(260-350)$ & $5.5(4.7-6.3)$ & $1100(1000-1200)$ & $6.3(5.4-7.2)$ \\
\hline $\begin{array}{l}\text { Year } 1 \text { to } 10 \\
2016-2025\end{array}$ & $2200(1900-2600)$ & $7.2(6.1-8.2)$ & $1200(1000-1300)$ & $5.6(4.9-6.1)$ & $3400(3000-3800)$ & $6.4(5.6-7.1)$ \\
\hline $\begin{array}{l}\text { Year } 1 \text { to } 15 \\
2016-2030\end{array}$ & $3400(3000-3900)$ & $7.3(6.3-8.2)$ & 2400 (2200-2600) & $5.6(5.1-6.1)$ & $5900(5200-6400)$ & $6.5(5.8-7.1)$ \\
\hline $\begin{array}{l}\text { Year } 1 \text { to } 20 \\
2016-2035\end{array}$ & $5700(4900-6400)$ & $7.2(6.2-8.1)$ & $4000(3700-4200)$ & $5.6(5.2-6.0)$ & 9600 (8700-10 500) & $6.4(5.9-7.0)$ \\
\hline $\begin{array}{l}\text { Year } 1 \text { to } 25 \\
2016-2040\end{array}$ & 8151 (7068-9199) & $7.1(6.2-8.0)$ & $5700(5300-6100)$ & $5.6(5.2-5.9)$ & $13900(12500-15100)$ & $6.4(5.8-7.0)$ \\
\hline
\end{tabular}

UI, uncertainty interval.

drop by $6.4 \%$ (95\% UI 5.6 to 7.1 ), being 3400 (95\% UI 3000 to 3800$)$ fewer deaths by 2025 . Over the lifetime, approximately 32300 (95\% UI 28700 to 35 900) IHD deaths would be prevented (table 1).

\section{Ischemic stroke incidence and mortality}

For ischaemic stroke, our model estimates a reduction in cumulative number of new cases by 5600 (5000 to $6300)$, a $7 \%$ (95\% UI 6.2 to 7.9 ) reduction in incidence by 2025. Over the lifetime, up to 22000 (19 400 to 24 $800)$ new cases of ischaemic stroke might be prevented. Numbers are similar for men and women, that is, 10700 (8800 to 12600 ) and 11400 (10 300 to 12500$)$, respectively. Mortality from ischaemic stroke is also projected to reduce by $4.5 \%$ (95\% UI 4.0 to 5.1$)$, that is, $10900(95 \%$ UI 9600 to 12 200) deaths prevented in both men and women (table 2).

\section{Haemorrhagic stroke incidence and mortality}

Our model projects that by 2025, the cumulative incidence of haemorrhagic stroke could decline by $9.4 \%$ (95\% UI 8.4 to 10.6$)$, that is, there might be $5200(95 \%$
UI 4600 to 5800) fewer new cases of haemorrhagic stroke due to reduction in salt intake. Over the lifetime of adults in 2016, the number of new cases could reduce by 20500 (95\% UI 18200 to 23000$)$. With respect to mortality, approximately 3100 (95\% UI 2700 to 3500) haemorrhagic stroke deaths could be prevented over the next 10 years (by 2025), while over the lifetime, the model predicts 17 700 (15 700 to 19 800) fewer deaths from haemorrhagic stroke, a $6.9 \%(95 \%$ UI 6.1 to 7.7$)$ reduction (table 3$)$.

\section{HHD incidence and mortality}

By 2025, our model projects approximately $4000(95 \%$ UI 3800 to 4100) fewer new cases of HHD for men and women combined, while over the lifetime, up to 19300 (95\% UI 18500 to 20100 ) incident cases of HHD could be prevented, corresponding to a $12.9 \%$ (95\% UI 12.4 to $13.5)$ reduction. The decline would be greater in women compared with men (table 4$)$. With respect to deaths, approximately 1000 (95\% UI 900 to 1100) HHD deaths could be prevented by 2025 , whereas over the lifetime, 10300 (95\% UI 10 000-10 500) HHD deaths could be 
Table 2 Reduction in incidence and mortality for ischaemic stroke by sex due to $30 \%$ reduction in salt intake in the 2016 adult Cameroonian population

\begin{tabular}{|c|c|c|c|c|c|c|}
\hline \multirow{3}{*}{$\begin{array}{l}\text { Year(s) } \\
\text { Incidence }\end{array}$} & \multicolumn{6}{|l|}{ Ischaemic stroke } \\
\hline & \multicolumn{2}{|l|}{ Male } & \multicolumn{2}{|l|}{ Female } & \multicolumn{2}{|l|}{ Total } \\
\hline & n (95\% UI) & $\%$ (95\% UI) & n (95\% UI) & \% (95\% UI) & n (95\% UI) & $\%$ (95\% UI) \\
\hline $\begin{array}{l}\text { Year } 1 \text { to } 10 \\
2016-2025\end{array}$ & $2800(2400-3200)$ & $7.7(6.6-8.9)$ & $2800(2500-3100)$ & $6.4(5.7-7.1)$ & $5600(5000-6300)$ & $7.0(6.2-7.9)$ \\
\hline $\begin{array}{l}\text { Year } 1 \text { to } 20 \\
2016-2035\end{array}$ & $5900(5000-6800)$ & $7.4(6.4-8.6)$ & $6000(5500-6500)$ & $6.1(5.6-6.7)$ & $11800(10600-13100)$ & $6.7(6.0-7.4)$ \\
\hline $\begin{array}{l}\text { Year } 1 \text { to } 25 \\
2016-2040\end{array}$ & $7300(6300-8400)$ & $7.2(6.2-8.3)$ & $7500(6900-8100)$ & $5.9(5.4-6.4)$ & $14800(13400-16300)$ & $6.5(5.9-7.2)$ \\
\hline \multicolumn{7}{|l|}{ Mortality } \\
\hline $\begin{array}{l}\text { Year } 1 \text { to } 5 \\
2016-2020\end{array}$ & $90(70-110)$ & $6.3(5.0-7.6)$ & $110(90-130)$ & $4.8(3.9-5.7)$ & $200(170-240)$ & $5.4(4.4-6.4)$ \\
\hline $\begin{array}{l}\text { Year } 1 \text { to } 10 \\
2016-2025\end{array}$ & $380(310-450)$ & $6.5(5.3-7.7)$ & $450(380-520)$ & $5.0(4.2-5.7)$ & $830(700-960)$ & $5.6(4.7-6.5)$ \\
\hline $\begin{array}{l}\text { Year } 1 \text { to } 15 \\
2016-2030\end{array}$ & $800(700-1000)$ & $6.6(5.5-7.7)$ & $1000(800-1100)$ & $5.1(4.5-5.7)$ & $1800(1600-2000)$ & $5.7(5.1-6.4)$ \\
\hline $\begin{array}{l}\text { Year } 1 \text { to } 20 \\
2016-2035\end{array}$ & $1400(1200-1600)$ & $6.8(5.6-7.8)$ & $1600(1400-1800)$ & $5.2(4.6-5.7)$ & $3000(2700-3400)$ & $5.9(5.3-6.5)$ \\
\hline $\begin{array}{l}\text { Year } 1 \text { to } 25 \\
2016-2040\end{array}$ & $2100(1800-2400)$ & $6.7(5.8-7.8)$ & $2400(2200-2600)$ & $5.2(4.7-5.7)$ & $4400(4000-4900)$ & $5.8(5.3-6.4)$ \\
\hline
\end{tabular}

UI, uncertainty interval.

prevented if current salt intakes were reduced by $30 \%$, corresponding to an overall $13.3 \%$ (95\% UI 12.9 to 13.7 ) reduction in mortality due to HHD.

\section{HALYs and life expectancy}

By the year 2025, our model predicts that reducing current salt intakes by $30 \%$ could gain 29200 (95\% UI 26 900 to 31 600) HALYs. By 2030, these gains are expected to increase to 75400 (95\% UI 69 800-81 200) HALYs, while over the lifetime, approximately 776400 (95\% UI 712600 to 841200 HALYs could be gained (table 5 and online supplementary file, figure 1). For adults aged $30-34$ years, an increase in life expectancy by 0.23 years for men and 0.20 years for women and an increment in health-adjusted life expectancy by 0.19 years for men and 0.17 years for women was estimated (online supplementary table 1).

\section{Probability of premature CVD mortality}

We estimate that the probability of a 30-year-old adult in Cameroon dying from CVD before age 70 years in 2016 is $16.7 \%$. Our model projects that this probability could be $15.4 \%$ in 2030 with current mortality rates. However, if populations reduce their salt intake by $30 \%$, the probability of premature CVD mortality decreases from $16.7 \%$ in 2016 to $13.9 \%$ (13.8\%-14.2\%) in 2030, corresponding to a $16.8 \%$ (percentage change) reduction (table 6 ).

\section{Sensitivity analysis}

In scenario analyses, a discount rate of $3 \%$ on health outcome reduces the number of HALYs projected in the base analysis by $59 \%$. An even greater reduction occurs when we apply a $5 \%$ discount rate. However, both scenarios still result in substantial numbers of HALYs gained, 322200 and 193 500, respectively. Over the lifetime, $20 \%$ reduction (ie, $1.13 \mathrm{~g} /$ day in men and 1.02 $\mathrm{g} /$ day in women) in salt intake could lead to 525,700 HALYs gained, while if just $10 \%$ (ie, $0.56 \mathrm{~g}$ /day in men and $0.50 \mathrm{~g} /$ day in women) reduction were achieved, approximately 282100 HALYs could be gained. Similarly, substantial reductions in incident cases and mortality from CVD might be achieved. Applying the salt-BP relationship (5.39 $\mathrm{mm} \mathrm{Hg}$ and $2.42 \mathrm{~mm} \mathrm{Hg}$ drop in SBP for 
Table 3 Reduction in incidence and mortality for haemorrhagic stroke due to $30 \%$ reduction in salt intake in the 2016 adult Cameroonian population

\begin{tabular}{|c|c|c|c|c|c|c|}
\hline \multirow{3}{*}{$\begin{array}{l}\text { Year(s) } \\
\text { Incidence }\end{array}$} & \multicolumn{6}{|c|}{ Haemorrhagic stroke } \\
\hline & \multicolumn{2}{|l|}{ Male } & \multicolumn{2}{|l|}{ Female } & \multicolumn{2}{|l|}{ Total } \\
\hline & n (95\% UI) & $\%(95 \%$ UI) & n (95\% UI) & $\%$ (95\% UI) & n (95\% UI) & $\%(95 \%$ UI) \\
\hline $\begin{array}{l}\text { Year } 1 \text { to } 10 \\
2016-2025\end{array}$ & $2900(2500-3400)$ & $10.5(9.0-12.1)$ & $2200(2000-2500)$ & $8.3(7.5-9.3)$ & $5200(4600-5800)$ & $9.4(8.4-10.6)$ \\
\hline $\begin{array}{l}\text { Year } 1 \text { to } 20 \\
2016-2035\end{array}$ & $6200(5400-7100)$ & $10.1(8.8-11.5)$ & $4800(4500-5200)$ & $8.1(7.4-8.7)$ & $11100(10000-12300)$ & $9.1(8.2-10.1)$ \\
\hline $\begin{array}{l}\text { Year } 1 \text { to } 25 \\
2016-2040\end{array}$ & $7700(6600-8800)$ & $9.7(8.4-11.2)$ & $6100(5600-6600)$ & $7.8(7.2-8.4)$ & 13800 (12 400-15 300) & $8.8(7.9-9.7)$ \\
\hline \multicolumn{7}{|l|}{ Mortality } \\
\hline $\begin{array}{l}\text { Year } 1 \text { to } 5 \\
2016-2020\end{array}$ & $570(480-670)$ & $10.4(8.8-12.3)$ & $400(360-470)$ & $8.0(6.9-9.1)$ & $1000(800-1100)$ & $9.3(8.0-10.7)$ \\
\hline $\begin{array}{l}\text { Year } 1 \text { to } 10 \\
2016-2025\end{array}$ & $1800(1500-2100)$ & $10.6(9.0-12.2)$ & $1300(1200-1500)$ & $8.2(7.3-9.2)$ & $3100(2700-3500)$ & $9.5(8.3-10.7)$ \\
\hline $\begin{array}{l}\text { Year } 1 \text { to } 15 \\
2016-2030\end{array}$ & $3200(2800-3700)$ & $10.6(9.2-12.1)$ & 2400 (2200-2600) & $8.3(7.5-9.1)$ & $5600(5000-6200)$ & $9.5(8.5-10.6)$ \\
\hline $\begin{array}{l}\text { Year } 1 \text { to } 20 \\
2016-2035\end{array}$ & $4700(4100-5400)$ & $10.5(9.111 .9)$ & 3600 (3300-3900) & $8.2(7.6-8.9)$ & $8300(7400-9100)$ & $9.4(8.4-10.4)$ \\
\hline $\begin{array}{l}\text { Year } 1 \text { to } 25 \\
2016-2040\end{array}$ & $6100(5300-7000)$ & $10.2(8.8-11.6)$ & $4700(4400-5100)$ & $8.0(7.4-8.7)$ & $10800(9800-12000)$ & $9.2(8.3-10.1)$ \\
\hline
\end{tabular}

UI, uncertainty interval.

hypertensive and normotensive, respectively, for every 4.4 $\mathrm{g}$ /day reduction in salt) obtained for all ethnic groups, as opposed to that in black ethnicity alone used for base analysis, approximately 667300 HALYs might still be gained.

\section{DISCUSSION}

Reduction in salt intake over the lifetime would significantly reduce the incidence of and mortality from CVDs. Together, well over 700000 HALYs will be gained if these salt reductions are achieved, including gains in health-adjusted life expectancy. Benefits were mostly greater in men compared with women. Our results were most sensitive to varied discount rates. Achieving this salt reduction could lead to a $16.8 \%$ change (reduction) in premature mortality from CVD between 2016 and 2030.

A modelled analysis for nine European countries ${ }^{20}$ found that a $30 \%$ reduction in population salt intake led to reduction in stroke prevalence by $6.4 \%$ in Finland and up to $13.5 \%$ in Poland. Modelling evidence from the $\mathrm{USA}^{21}$ and India $^{22}$ have predicted similar substantial health gains. Although previous studies all found similar outcomes, authors have generally used different modelling approaches. For instance, the European study ${ }^{20}$ used the DYNAMO-HIA model, a dynamic population model that takes into account changing population demographics (allowing new birth cohorts), contrary to our approach that does not. However, studies in New Zealand $^{23}$ and Australia ${ }^{24}$ have used the same proportional MSLT modelling approach and obtained similar health gains as observed in our study. The impact of other risk factors such as tobacco use, body mass index (BMI) and cholesterol known to influence CVD outcomes were not included or adjusted for in our model. While most salt-CVD modelling studies have similarly not taken them into account, ${ }^{20} 22{ }^{24}$ Bibbins-Domingo et al compared the effects of salt reduction on CVD events with other risk factor interventions. They found that a reduction of $3 \mathrm{~g}$ per day in population salt intake yielded similar effects on the incidence of coronary heart disease as a $50 \%$ reduction in tobacco use, a $5 \%$ reduction in BMI in obese adults, or the use of statins in individuals 
Table 4 Reduction in incidence and mortality for hypertensive heart disease by sex due to $30 \%$ reduction in salt intake in the 2016 adult Cameroonian population

\begin{tabular}{|c|c|c|c|c|c|c|}
\hline \multirow{3}{*}{$\begin{array}{l}\text { Year(s) } \\
\text { Incidence }\end{array}$} & \multicolumn{6}{|c|}{ Hypertensive heart disease } \\
\hline & \multicolumn{2}{|l|}{ Male } & \multicolumn{2}{|l|}{ Female } & \multicolumn{2}{|l|}{ Total } \\
\hline & n (95\% UI) & $\%$ (95\% UI) & n (95\% UI) & \% (95\% UI) & n (95\% UI) & $\%$ (95\% UI) \\
\hline $\begin{array}{l}\text { Year } 1 \text { to } 5 \\
2016-2020\end{array}$ & $780(700-840)$ & $19.5(17.8-21.2)$ & $1180(1170-1190)$ & $16.0(15.8-16.2)$ & $2000(1900-2100)$ & $17.2(16.6-17.9)$ \\
\hline $\begin{array}{l}\text { Year } 1 \text { to } 10 \\
2016-2025\end{array}$ & $1500(1400-1700)$ & $19.0(17.3-20.6)$ & $2400(2300-2500)$ & $15.8(15.7-15.9)$ & $4000(3800-4100)$ & $16.9(16.3-17.5)$ \\
\hline $\begin{array}{l}\text { Year } 1 \text { to } 15 \\
2016-2030\end{array}$ & $2300(2100-2500)$ & $18.5(16.8-20.1)$ & $3700(3600-3800)$ & $15.5(15.4-15.6)$ & $6000(5800-6200)$ & $16.5(15.9-17.1)$ \\
\hline $\begin{array}{l}\text { Year } 1 \text { to } 20 \\
2016-2035\end{array}$ & $3000(2700-3300)$ & $17.9(16.2-19.5)$ & $5000(4900-5100)$ & $15.0(14.9-15.1)$ & $8000(7700-8300)$ & $16.0(15.4-16.5)$ \\
\hline $\begin{array}{l}\text { Year } 1 \text { to } 25 \\
2016-2040\end{array}$ & $3800(3400-4100)$ & $17.3(15.6-18.9)$ & $6300(6200-6,400)$ & $14.5(14.4-14.6)$ & $10000(9700-10400)$ & $15.4(14.8-15.9)$ \\
\hline $\begin{array}{l}\text { Year } 1 \text { to } 30 \\
2016-2045\end{array}$ & $4600(4200-5000)$ & $16.7(15.2-18.3)$ & $7500(7400-7600)$ & $14.0(13.9-14.1)$ & $12200(11700-12600)$ & $14.9(14.4-15.4)$ \\
\hline Lifetime & $7300(6400-8100)$ & $15.2(13.5-17.0)$ & $12000(11900-12$ 100) & $11.9(11.8-12.0)$ & $19300(18$ 500-20 100) & $12.9(12.4-13.5)$ \\
\hline \multicolumn{7}{|l|}{ Mortality } \\
\hline $\begin{array}{l}\text { Year } 1 \text { to } 5 \\
2016-2020\end{array}$ & $60(55-70)$ & $20.1(18.1-22.1)$ & $205(200-210)$ & $14.7(14.6-14.8)$ & $270(260-280)$ & $15.8(15.3-16.1)$ \\
\hline $\begin{array}{l}\text { Year } 1 \text { to } 10 \\
2016-2025\end{array}$ & $220(200-240)$ & $19.3(17.6-21.0)$ & $740(730-750)$ & $14.9(14.8-15.0)$ & $1000(900-1100)$ & $15.7(15.4-16.0)$ \\
\hline $\begin{array}{l}\text { Year } 1 \text { to } 15 \\
2016-2030\end{array}$ & $440(400-480)$ & $19.2(17.5-20.9)$ & $1480(1470-1490)$ & $15.1(15.0-15.2)$ & 1900 (1800-2000) & $15.9(15.6-16.3)$ \\
\hline $\begin{array}{l}\text { Year } 1 \text { to } 20 \\
2016-2035\end{array}$ & $720(660-790)$ & $19.1(17.4-20.8)$ & 2370 (2360-2380) & $15.2(15.1-15.3)$ & $3100(3000-3200)$ & $16.0(15.7-16.4)$ \\
\hline $\begin{array}{l}\text { Year } 1 \text { to } 25 \\
2016-2040\end{array}$ & $1030(930-1100)$ & $18.9(17.2-20.6)$ & 3340 (3330-3350) & $15.2(15.1-15.3)$ & $4400(4300-4500)$ & $15.9(15.5-16.2)$ \\
\hline $\begin{array}{l}\text { Year } 1 \text { to } 30 \\
2016-2045\end{array}$ & $1400(1200-1500)$ & $18.6(16.8-20.3)$ & 4350 (4330-4360) & $14.9(14.8-15.0)$ & $5700(5600-5800)$ & $15.7(15.3-16.1)$ \\
\hline Lifetime & 2500 (2200-2700) & $12.6(12.5-12.8)$ & 7700 (7600-7800) & $12.6(12.5-12.7)$ & $10300(10000-10500)$ & $13.3(12.9-13.7)$ \\
\hline
\end{tabular}

UI, uncertainty interval.

at low or intermediate risk of CVD. This $3 \mathrm{~g}$ salt reduction produced larger benefits with stroke prevention compared with the other risk factor interventions and an equivalent reduction in mortality rates as antihypertensive drug treatment in affected adults. ${ }^{21}$ Second, the study by Basu et al $t^{22}$ provided estimates over a 30 -year period, the US study over a decade, while we model over the remaining lifetime of the population until they reach 100 years or die. Some authors have modelled lag reversal in risk of stroke and $\mathrm{IHD}^{22}{ }^{24}$; in our model, we do not consider those. However, Cobiac and colleagues found similar outcomes with and without incorporating risk

Table 5 Health-adjusted life years gained due to a potential 30\% reduction in current salt intake among Cameroonian adults

\begin{tabular}{|c|c|c|c|}
\hline & Male & Female & Total \\
\hline Year(s) & Mean (95\% UI) & Mean (95\% UI) & Mean (95\% UI) \\
\hline Year 1 to 5, 2016-2020 & $3000(2600-3400)$ & $2600(2400-2700)$ & $5500(5100-6000)$ \\
\hline Year 1 to $10,2016-2025$ & $15700(13900-17600)$ & 13500 (12 800-14 200) & $29200(26900-31600)$ \\
\hline Year 1 to $15,2016-2030$ & 40600 (35 800-45 400) & 34800 (33 200-36 500) & 75400 (69 800-81 200) \\
\hline Year 1 to $20,2016-2035$ & 77500 (68 300-86 600) & 66800 (64 100-69 600) & 144300 (133 700-155 100) \\
\hline Year 1 to $25,2016-2040$ & 124700 (109 400-139500) & 108400 (104 300-112 300) & 233100 (215 700-250 300) \\
\hline Year 1 to $30,2016-2045$ & 178800 (155 800-201 000) & 157600 (152 200-162 800) & 336300 (311 400-360 500) \\
\hline Lifetime & 392000 (331 700-451 200) & 384500 (371 200-397 500) & 776400 (712 600-841 200) \\
\hline
\end{tabular}

UI, uncertainty interval. 
Table 6 Potential change in premature mortality from the four cardiovascular diseases (CVD) between 2016 and 2030 in Cameroon following a $30 \%$ reduction in population salt intake

\begin{tabular}{|c|c|c|c|c|c|}
\hline \multirow[b]{2}{*}{ Year } & \multirow{2}{*}{$\begin{array}{l}\text { Base year } \\
2016\end{array}$} & \multirow{2}{*}{$\begin{array}{l}\text { Without salt } \\
\text { reduction }\end{array}$} & \multirow{2}{*}{$\begin{array}{l}\begin{array}{l}\text { With salt } \\
\text { reduction }\end{array} \\
2030\end{array}$} & \multicolumn{2}{|c|}{ Percentage change } \\
\hline & & & & $\begin{array}{l}2016-2030 \\
\text { (without salt } \\
\text { reduction) }\end{array}$ & $\begin{array}{l}2016-2030 \\
\text { (with salt } \\
\text { reduction) }\end{array}$ \\
\hline \multicolumn{6}{|l|}{ Men } \\
\hline No of premature CVD deaths & 4500 & 6900 & 6000 & +53.3 & +33.3 \\
\hline $\begin{array}{l}\text { Premature mortality rate from CVDs* per } 100 \\
000 \text {; estimate }(95 \% \mathrm{Cl})\end{array}$ & $\begin{array}{l}139.3 \\
(135.2 \text { to } 143.4)\end{array}$ & $\begin{array}{l}129.0 \\
(126.0 \text { to } 132.0)\end{array}$ & $\begin{array}{l}111.9 \\
(109.0 \text { to } 114.7)\end{array}$ & -7.4 & -19.7 \\
\hline Premature mortality probability from CVDs* $\%$ & 9.5 & 8.9 (8.9 to 8.9$)$ & 8.1 (8.0 to 8.3$)$ & -6.3 & -14.7 \\
\hline \multicolumn{6}{|l|}{ Women } \\
\hline No of premature CVD deaths & 3300 & 4900 & 4300 & +48.5 & +30.3 \\
\hline $\begin{array}{l}\text { Premature mortality rate from CVDs* per } 100 \\
000 \text {; estimate }(95 \% \mathrm{Cl})\end{array}$ & $\begin{array}{l}101.2 \\
(97.8 \text { to } 104.7)\end{array}$ & $\begin{array}{l}89.8 \\
(87.3 \text { to 92.3) }\end{array}$ & $\begin{array}{l}78.5 \\
(76.1 \text { to } 80.8)\end{array}$ & -11.3 & -22.4 \\
\hline Premature mortality probability from CVDs* $\%$ & 7.2 & 6.5 (6.5 to 6.5$)$ & 6.0 (5.9 to 6.0$)$ & -9.7 & -16.7 \\
\hline \multicolumn{6}{|l|}{ Total } \\
\hline No of premature CVD deaths & 7800 & 11900 & 10300 & +52.6 & +32.1 \\
\hline $\begin{array}{l}\text { Premature mortality rate from CVDs* per } 100 \\
000 \text {; estimate }(95 \% \mathrm{CI})\end{array}$ & $\begin{array}{l}120.1 \\
(117.4 \text { to } 122.8)\end{array}$ & $\begin{array}{l}109.2 \\
(107.2 \text { to } 111.1)\end{array}$ & $\begin{array}{l}95.0 \\
(93.2 \text { to } 96.8)\end{array}$ & -9.1 & -20.8 \\
\hline Premature mortality probability from CVDs*, \% & 16.7 & $15.4(15.4$ to 15.4$)$ & 13.9 (13.8 to 14.2$)$ & -7.8 & -16.8 \\
\hline
\end{tabular}

Rates refer to the cumulative mortality rates for adults aged between 30 and 70 years, expressed per 100000 population. Mortality probabilities refer to the unconditional probability that an adult aged 30 years will die before their 70 th birthday in the year 2030 . These are presented for the base year of analysis (2016), then without and with the projected $30 \%$ salt reduction to estimate the potential change. ${ }^{*}$ CVDs include ischaemic heart disease, ischaemic stroke, haemorrhagic stroke and hypertensive heart disease.

reversal lag. ${ }^{24}$ Contrary to our approach, other authors have modelled annual gradual reductions in salt intake on $\mathrm{CVD},{ }^{22}$ and these have yielded similarly large health gains as those observed in our study. Hendriksen and colleagues previously investigated the differences in health impact assessment methods used for modelling salt reduction. ${ }^{25}$ They compared seven population health models including the DYNAMO-HIA, the proportional MSLT and the coronary heart disease policy model and found that the size and shape of the salt and BP dose-response as well as BP and CVD relationships influenced model outcomes with up to $33 \%$ maximum variation. Our reporting of outcomes that are broadly consistent with findings elsewhere, despite differences in model structure, potentially point to the robustness and validity of our findings.

More tangibly, examples of successful salt reduction strategies and their effect on BP and CVD have been noted. About a decade following implementation of a government-led campaign in Japan, there was a relative reduction in daily salt intake by over $28 \%$ (from $18 \mathrm{~g}$ to $14 \mathrm{~g}$ ), which was accompanied by an almost $80 \%$ fall in stroke mortality. ${ }^{13}$ Similarly, in Finland, average daily salt intake declined by a third over a period of almost three decades, thanks to a programme that included salt-awareness campaigns, legislation for salt labelling and working with the food industry. This led to a drop of more than $10 \mathrm{~mm} \mathrm{Hg}$ in both systolic and diastolic BP, along with a $75 \%-80 \%$ decline in cardiovascular deaths. ${ }^{26}$ More recently, the UK implemented a programme including a media campaign and voluntary salt reduction by the food industry that led to a reduction in salt intake by around $15 \%$ in just under a decade (2003 to 2011). This resulted in a significant reduction in mean population $\mathrm{BP}$ and declines in stroke and IHD deaths. ${ }^{13}$ These successful strategies could serve as model for other countries.

Global and regional/country modelling studies suggest that if specific NCD risk factor targets proposed by WHO are met, the decline in premature mortality of $25 \%$ by $2025^{27} 28$ and one-third by 2030 for Sustainable Development Goals $(\mathrm{SDG})^{29}$ can be achieved in some countries or regions but not in others. Our projections reveal almost $17 \%$ change reduction in premature CVD mortality probability between 2016 and 2030 if the salt reduction target is attained in Cameroon. This is more than halfway through to meeting the expected $30 \%$ reduction for NCDs by 2030 and demonstrates the strong impact that population salt reduction could have on BP and CVD mortality. Nonetheless, these findings imply that there is a need for efforts on or combining other risk factor targets, to ensure attainment of the SDG premature mortality target in Cameroon.

\section{Strengths and limitations}

A limitation in this study is that our modelling does not take into account changes in population demographics, 
such as trends in fertility (incorporate new birth cohorts over time) and migration that modify the age structure of the population over time. Second, in terms of diseases and risk factors, other diseases linked to high salt intake such as osteoporosis, kidney disease and gastric cancer are not modelled. We did not include these because the causal link with salt intake is not as strong as that for CVDs. Taken together, these suggest our reported health gains are likely conservative. Where previous studies have modelled two diseases, IHD and all stroke, ${ }^{21}{ }^{22}$ we explicitly modelled IHD, the two major types of stroke separately and HHD. Third, with respect to model inputs, there are no large nationally representative population-based longitudinal studies on CVD in Cameroon. As a result, our disease burden (incidence and mortality) and relative risk estimates relied on those from the GBD. We used BP data from a nationwide study obtained predominantly from urban settings. ${ }^{3}$ Our assumption that this applies to rural areas is supported by studies in Cameroon, as well as meta-analysis of studies from sub-Saharan Africa, that have reported similar hypertension prevalence in rural and urban areas. ${ }^{30}$ The nationwide study used does suggest the existence of regional differences in hypertension prevalence in Cameroon. Future modelling efforts could explore the impacts of such differences. For baseline sodium intake, we used estimates from a Total Diet survey that sampled foods constituting over $96.5 \%$ of the average Cameroonian diet. ${ }^{32}$ Given consumption data used in this study were mostly from household budget survey, and foods were prepared in the study laboratory without any addition of salt/stock cubes and condiments/spices (which are normally added during cooking in Cameroon), the sodium intake level reported is largely an underestimate as acknowledged by the authors. ${ }^{32}$ This implies our predicted model outcomes are likely conservative.

Apart from efforts in South Africa, ${ }^{12}$ to our knowledge, no study in Africa has assessed the lifetime impact of population salt reduction as proposed by WHO. Our study is the first of such studies. Using the proportional MSLT method, we explicitly model changes in risk factor distribution, disease incidence, prevalence and mortality, including future life years while adjusting for disease-specific disability, and comorbidity. By calculating summary measures of population health such as HALYs, which incorporate morbidity and mortality, it aids in comparability of our findings across other domains. The lifetable approach additionally provides estimates for changes in life expectancy, which are otherwise seldom reported in modelling studies. Furthermore, given the time horizon (lifetime) used, our study provides a comprehensive picture of the potential health gains due to salt reduction, as opposed to trials or other modelled evaluations with shorter duration. This study is the first to estimate the impact of salt reduction on the probability of premature GVD mortality, which is important to inform the Ministry of Health on strategies to attain the SDGs by 2030.
We assume a dose-response salt-BP-CVD relationship in our study, supported by evidence from cohort and interventional studies; ${ }^{7}$ some authors propose a non-linear relationship, being either U-shaped or J-shaped with increased risk of mortality with low and high salt intake. ${ }^{33}$ Most of the latter studies had methodological shortcomings such as measurement errors with quantification of sodium excretion, reverse causality and short intervention duration, which made them less valid from a public health perspective. ${ }^{13} 34$

\section{Implications for policy and future research}

In Cameroon, there is currently no policy towards reducing salt intake and even more broadly, absence of robust strategies and interventions for the prevention of CVD. Recent evidence from low-income and middle-income countries (LMICs) suggests that interventions targeting salt intake at population levels are cost-saving ${ }^{35}$ and do also reduce out-of-pocket expenses and provide financial risk protection via averting catastrophic health expenditures. ${ }^{12}$ Thus, it is important for the Ministry of Health and other policy-makers to consider salt reduction interventions as part of combined strategies to reduce disease burden. These strategies have to be guided by knowledge of the sources of salt in the diet. A good start would be to increase awareness with media campaigns and public education on the ills of high salt diets, as studies suggest that the major sources of salt intake in Cameroon like most LMICs are from discretionary addition during cooking and at table. ${ }^{13}$

Future studies should include equity considerations, such as rural-urban differences, socioeconomic status and ethnic variations. Local, context-specific cost-effectiveness analyses of potential interventions targeting salt reduction could be conducted to better inform policy decisions.

\section{CONCLUSION}

This study provides model-based evidence on the potential impact of population-wide reduction in salt intake if the WHO recommendations were achieved in Cameroon. Our findings may be generalised to other African countries with similar epidemiological backgrounds, to join the global and public health recommendations to engage in population-wide reductions in salt intake. Future studies looking at the economic evaluation of potential salt reduction interventions are warranted to further inform policy.

Contributors LNA conceived the study, did the modeling analysis and wrote the first version of the manuscript. LJC and JLV contributed to analysis, interpretation of findings and reviewed successive versions of the manuscript. All authors critically reviewed the manuscript and approved the final version for publication.

Funding Leopold N. Aminde is supported by the Australian Government Research Training Program (RTP) Scholarship Award.

Competing interests None declared.

Patient consent for publication Not required. 
Ethics approval This study was approved by the School of Public Health Research Ethics Committee of the University of Queensland, Australia (no. 1708).

Provenance and peer review Not commissioned; externally peer reviewed.

Open access This is an open access article distributed in accordance with the Creative Commons Attribution Non Commercial (CC BY-NC 4.0) license, which permits others to distribute, remix, adapt, build upon this work non-commercially, and license their derivative works on different terms, provided the original work is properly cited, appropriate credit is given, any changes made indicated, and the use is non-commercial. See: http://creativecommons.org/licenses/by-nc/4.0/.

\section{REFERENCES}

1. Roth GA, Johnson C, Abajobir A, et al. Global, regional, and national burden of cardiovascular diseases for 10 causes, 1990 to 2015 . J Am Coll Cardiol 2017;70:1-25.

2. Adeloye D, Basquill C. Estimating the prevalence and awareness rates of hypertension in Africa: a systematic analysis. PLOS ONE 2014:9:e104300.

3. Kingue S, Ngoe CN, Menanga AP, et al. Prevalence and risk factors of hypertension in urban areas of Cameroon: a nationwide population-based cross-sectional study. J Clin Hypertens 2015;17:819-24.

4. Lekoubou A, Nkoke C, Dzudie A, et al. Stroke admission and casefatality in an urban medical unit in sub-Saharan Africa: a fourteen year trend study from 1999 to 2012. J Neurol Sci 2015;350:24-32.

5. Nkoke C, Makoge C, Dzudie A, et al. A predominance of hypertensive heart disease among patients with cardiac disease in Buea, a semi-urban setting, South West region of Cameroon. BMC Res Notes 2017;10:684.

6. World Health Organization. Global Action Plan for the prevention and control of noncommunicable diseases 2013-2020. Geneva: WHO, 2013.

7. He FJ, Li J, MacGregor GA, et al. Effect of longer-term modest salt reduction on blood pressure. Cochrane Database Syst Rev 2013;1.

8. Global Nutrition and Policy Consortium. The global dietary database: measuring diet in countries worldwide. Tufts Friedman School of Nutrition Science and Policy, 2014.

9. World Health Organization. Shake the salt habit: the shake technical package for salt reduction. Geneva: WHO, 2016.

10. Eckel RH, Jakicic JM, Ard JD, et al. 2013 AHA/ACC guideline on lifestyle management to reduce cardiovascular risk: a report of the American College of Cardiology/American Heart Association Task Force on practice guidelines. J Am Coll Cardiol 2014;63:2960-84.

11. National Institute for Health and Care Excellence (NICE). Cardiovascular disease prevention. UK: NICE, 2010.

12. Watkins DA, Olson ZD, Verguet S, et al. Cardiovascular disease and impoverishment averted due to a salt reduction policy in South Africa: an extended cost-effectiveness analysis. Health Policy Plan. 2016;31:75-82.

13. He FJ, MacGregor GA. Role of salt intake in prevention of cardiovascular disease: controversies and challenges. Nat Rev Cardiol 2018;15:371-7.

14. Gakidou E, Afshin A, Abajobir AA, et al. Global, regional, and national comparative risk assessment of 84 behavioural, environmental and occupational, and metabolic risks or clusters of risks, 1990-2016: a systematic analysis for the Global Burden of Disease Study 2016. Lancet 2017;390:1345-422.

15. Barendregt JJ, van Oortmarssen GJ, Vos T, et al. A generic model for the assessment of disease epidemiology: the computational basis of DisMod II. Popul Health Metr 2003;1:4.
16. Barendregt JJ, Van Oortmarssen GJ, Van Hout BA, et al. Coping with multiple morbidity in a life table. Math Popul Stud 1998;7:29-49.

17. Barendregt JJ, Veerman JL. Categorical versus continuous risk factors and the calculation of potential impact fractions. J Epidemiol Community Health 2010;64:209-12.

18. World Health Organization. Noncommunicable disease progress monitor 2017. Geneva: WHO, 2017.

19. Barendregt JJ. Ersatz. EpiGear international. Brisbane, QLD. Available: www.epigear.com

20. Hendriksen MAH, van Raaij JMA, Geleijnse JM, et al. Health gain by salt reduction in Europe: a modelling study. Plos One 2015;10:e0118873.

21. Bibbins-Domingo K, Chertow GM, Coxson PG, et al. Projected effect of dietary salt reductions on future cardiovascular disease. $N$ Engl J Med 2010;362:590-9.

22. Basu S, Stuckler D, Vellakkal S, et al. Dietary salt reduction and cardiovascular disease rates in India: a mathematical model. PLoS ONE 2012;7:e44037.

23. Wilson $\mathrm{N}$, Nghiem $\mathrm{N}$, Eyles $\mathrm{H}$, et al. Modeling health gains and cost savings for ten dietary salt reduction targets. Nutr $J$ 2015;15:44.

24. Cobiac LJ, Vos T, Veerman JL. Cost-effectiveness of interventions to reduce dietary salt intake. Heart 2010;96:1920-5.

25. Hendriksen MAH, Geleijnse JM, van Raaij JMA, et al. Identification of differences in health impact modelling of salt reduction. Plos One 2017;12:e0186760.

26. Karppanen H, Mervaala E. Sodium intake and hypertension. Prog Cardiovasc Dis 2006;49:59-75.

27. Roth GA, Nguyen G, Forouzanfar MH, et al. Estimates of global and regional premature cardiovascular mortality in 2025. Circulation 2015;132:1270-82

28. Kontis V, Mathers CD, Bonita R, et al. Regional contributions of six preventable risk factors to achieving the $25 \times 25$ non-communicable disease mortality reduction target: a modelling study. Lancet Glob Health 2015;3:e746-57.

29. Li Y, Zeng X, Liu J, et al. Can China achieve a one-third reduction in premature mortality from non-communicable diseases by $2030 ?$ BMC Medicine 2017;15:132.

30. Arrey WT, Dimala CA, Atashili J, et al. Hypertension, an emerging problem in rural Cameroon: prevalence, risk factors, and control. Int $J$ Hypertens 2016;2016:1-6.

31. Ataklte F, Erqou S, Kaptoge S, et al. Burden of undiagnosed hypertension in sub-Saharan Africa: a systematic review and metaanalysis. Hypertension 2015;65:291-8.

32. Gimou MM, Charrondiere UR, Leblanc JC, et al. Dietary exposure and health risk assessment for 11 minerals and trace elements in Yaounde: the Cameroonian Total Diet Study. Food additives \& contaminants Part A, Chemistry, analysis, control, exposure \& risk assessment 2013;30:1556-72.

33. Mente A, O'Donnell M, Rangarajan S, et al. Associations of urinary sodium excretion with cardiovascular events in individuals with and without hypertension: a pooled analysis of data from four studies. Lancet 2016;388:465-75.

34. Cogswell ME, Mugavero K, Bowman BA, et al. Dietary Sodium and Cardiovascular Disease Risk--Measurement Matters. N Engl J Med 2016;375:580-6.

35. Aminde LN, Takah NF, Zapata-Diomedi B, et al. Primary and secondary prevention interventions for cardiovascular disease in low-income and middle-income countries: a systematic review of economic evaluations. Cost Eff Resour Alloc 2018;16:22. 